03.1

\title{
Волновая структура пленок жидкости при переходе к турбулентному режиму течения
}

\author{
(C) А.В. Бобылев, С.М. Харламов, В.В. Гузанов, А.З. Квон, Д.М. Маркович \\ Институт теплофизики им. С.С. Кутателадзе СО РАН, Новосибирск, Россия \\ E-mail: bobylev@itp.nsc.ru
}

Поступило в Редакцию 25 февраля 2019г.

В окончательной редакции 25 апреля 2019 .

Принято к публикации 25 апреля 2019г.

\begin{abstract}
Приводятся результаты экспериментального исследования волн на поверхности вертикально стекающей пленки жидкости в диапазоне чисел Рейнольдса пленочного течения $80<\mathrm{Re}<420$. Эксперименты проводились с использованием полевых оптических методов диагностики с высоким пространственным и временны́м разрешением. На гребнях крупных трехмерных волн зафиксирована генерация капиллярной ряби с малой длиной волны. Как отмечается в литературе, именно в этих областях трехмерных волн наблюдаются так называемые „пятна турбулентности“, с появлением которых связывается переход к турбулентному режиму течения. Также зарегистрированы долгоживущие округлые впадины с характерными поперечными размерами 1-3 mm, которые формируются в области взаимодействия капиллярных предвестников и затем распространяются как независимые структурные элементы течения.
\end{abstract}

Ключевые слова: стекающая пленка жидкости, 3D-волны, турбулентное течение, лазерно-индуцированная флуоресценция.

DOI: 10.21883/PJTF.2019.15.48078.17754

По современным представлениям для вертикально стекающих пленок жидкости плавный переход от ламинарного волнового к турбулентному волновому режиму течения происходит в диапазоне чисел Рейнольдса $100<\operatorname{Re}<400$ [1]. Здесь $\operatorname{Re}=q / v, q$ - удельный объемный расход жидкости, $v$ - кинематическая вязкость. Как правило, в промышленных установках, где встречается пленочное течение, реализуются режимы, которые соответствуют диапазону Re от 50 до 1000 [2]. Таким образом, особенности переходных к турбулентности режимов течения должны оказывать существенное влияние на эффективность работы технологического оборудования. В то же время волновые характеристики пленок жидкости в переходных режимах исследованы недостаточно подробно, что связано с техническими ограничениями методов измерения и сложной трехмерной (3D) волновой структурой течения. Использование полевых методов измерения предоставляет большие возможности для исследования трехмерных волновых режимов пленочного течения и соответственно позволяет уточнить существующую классификацию режимов течения в зависимости от числа Рейнольдса и геометрических параметров задачи. В настоящее время с использованием широко применяемого метода теневой визуализации наряду с методами локальных измерений подробно описаны двумерные (2D) режимы течения в различной геометрии, в том числе и на вертикально стекающей пленке [1]. С применением полевого метода флуоресцентной визуализации и его модификации - метода лазерно-индуцированной флуоресценции (ЛИФ) исследованы сценарии перехода от 2D- к 3D-волновым режимам течения пленок для случаев наклонной и вертикальной пластины $[3,4]$. С использованием полевых методов измерений в ряде работ [5-7] получена детальная информация о различных структурных элементах волновых полей и проведена классификация 3D-волновых режимов течения для чисел Рейнольдса $\operatorname{Re}<100$. Вместе с тем в литературе можно найти совсем немного экспериментальных работ, в которых полевыми методами исследуется волновая структура пленки при переходе к турбулентному режиму течения. Одной из таких публикаций является работа [5], в которой исследовались волновые режимы течения на вертикально стекающей пленке жидкости при $27<\mathrm{Re}<200$. В [5] при $\operatorname{Re}>70$ методом флуоресцентной визуализации на гребнях крупных 3D-волн были обнаружены области оптической засветки, которые авторы объясняют наличием в этих областях „пятен турбулентности“, где за счет турбулизации пленки ее поверхность имеет большие углы наклона по отношению к стенке канала, что и приводит к засветкам в использованной авторами компоновке измерительной системы. Частота появления пятен засветки, их количество и размеры растут с увеличением числа Рейнольдса. Авторы [5] использовали компоновку оптической системы, при которой возбуждение и регистрация флуоресценции осуществляются со стороны прозрачной стенки, по противоположной стороне которой стекает пленка. При такой компоновке засветка возникает из-за фокусировок отраженного света под волновой поверхностью пленки и в тех областях, где наклон свободной поверхности пленки приближается к углу полного внутреннего отражения или превосходит его. Из-за ограничений метода флуоресцентной визуализации в данной компоновке волновая структура этих 


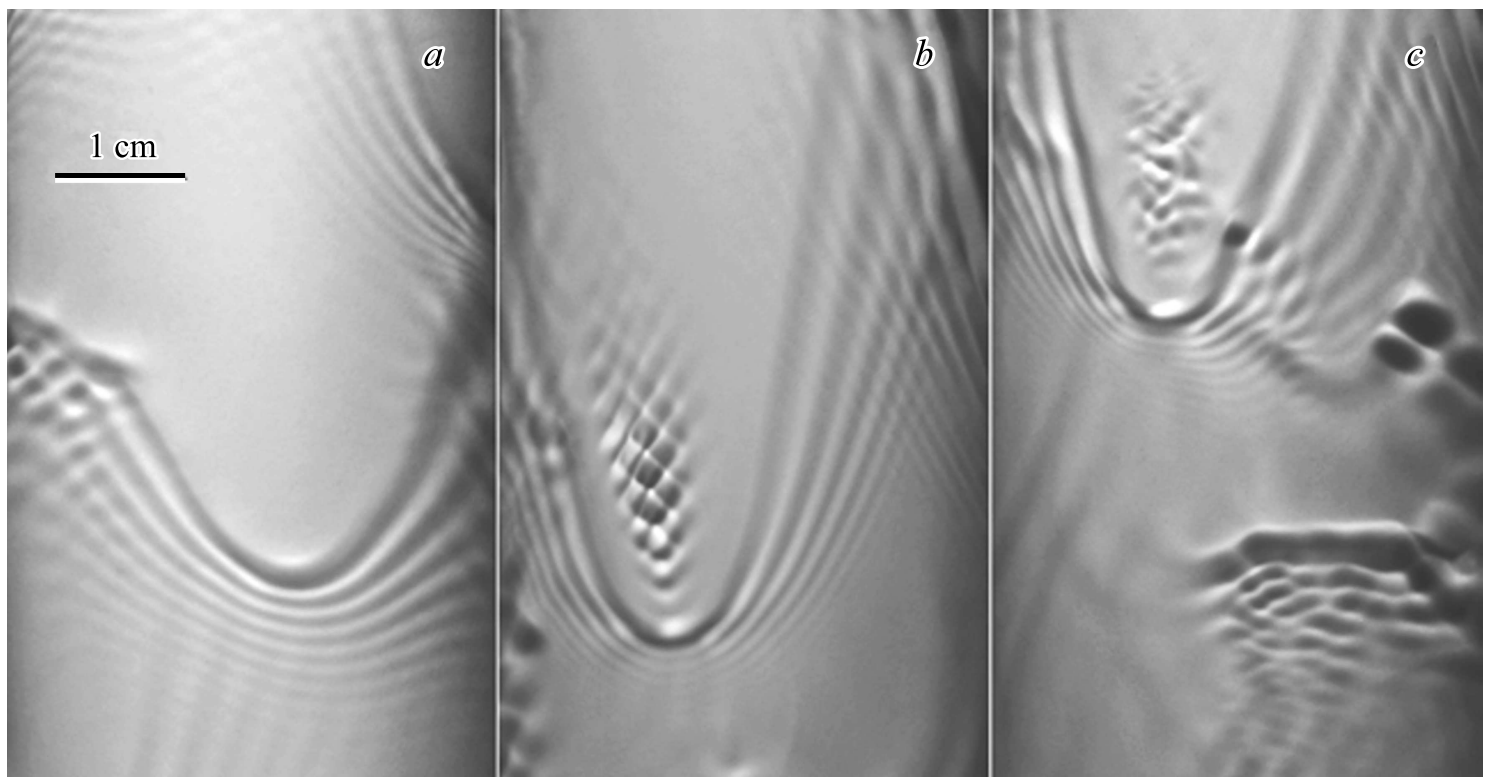

Рис. 1. Теневые снимки трехмерных волн в области установившегося течения на расстоянии $80 \mathrm{~cm}$ от распределителя, ВГР. $a-3 \mathrm{D}$-волна с гладким гребнем при $\mathrm{Re}=80, b-$ ячеистая структура на поверхности 3D-волны при $\mathrm{Re}=190, c-$ размывание ячеистой структуры при $\mathrm{Re}=220$.

пятен остается неисследованной, а области засветки считаются участками турбулентного течения, с появлением и дальнейшим ростом которых начинается переход к турбулентному пленочному течению $[5,8]$. В связи с этим возникает вопрос об исследовании волновой структуры „пятен турбулентности“ с использованием оптической схемы измерения, позволяющей разрешить мелкомасштабные элементы волновой поверхности пленки жидкости. Задачей настоящей работы является экспериментальное исследование волновой поверхности пленки в переходных к турбулентному режимах пленочного течения, в которых наблюдаются „пятна турбулентности“.

Эксперименты проводились на прозрачной вертикальной пластине размером $45 \times 140 \mathrm{~cm}$ (детальное описание установки можно найти в [7]) и внешней поверхности вертикального цилиндра диаметром $60 \mathrm{~mm}$ и высотой $150 \mathrm{~cm}$. Исследовались режимы пленочного течения с естественной волновой эволюцией на воде и $25 \%$ водоглицериновом растворе (ВГР) с плотностью $\rho=1.06 \mathrm{~g} / \mathrm{cm}^{3}$ и $v=1.7 \cdot 10^{-2} \mathrm{~cm}^{2} / \mathrm{s}$ в диапазоне чисел Рейнольдса $80<\operatorname{Re}<420$. В работе применялись скоростные полевые методы ЛИФ и теневой визуализации [7]. С их помощью были получены общие картины течения по всей длине рабочего участка (теневой метод) и локальные распределения толщины волновой пленки жидкости в областях размером от $4 \times 13$ до $15 \times 15 \mathrm{~cm}$ с разрешением $0.13 \mathrm{~mm}$ на пиксель на расстояниях до $1.4 \mathrm{~m}$ от щелевого пленкоформирователя (методом ЛИФ). Во всех случаях съемка течения осуществлялась скоростной камерой с частотой $1 \mathrm{kHz}$, временем экспозиции $1 \mathrm{~ms}$ и длительностью $2 \mathrm{~s}$, что позволило наблюдать в динамике особенности волновой эволюции исследованных режимов. При использовании метода ЛИФ в рабочей жидкости растворялся Родамин 6Ж в количествах 20-30 mg/1, флуоресценция которого возбуждалась непрерывным лазером зеленого цвета. В отличие от [5] освещение и регистрация осуществлялись со стороны свободной поверхности пленки, что позволило избавиться от ряда причин, приводящих к засветке полученных изображений. При использованной нами компоновке измерительной системы не возникает случаев полного внутреннего отражения света внутри пленки жидкости, а фокусировки под волновой поверхностью пленки происходят на расстояниях, в 7-8 раз бо́льших, чем в работе [5], что позволяет без существенных искажений разрешить мелкомасштабную структуру, возникающую на гребнях больших волн.

Сопоставление волновых картин течения для случаев пластины и цилиндра показало, что тип рабочего участка не влияет на волновую структуру течения. Незначительные различия в волновых режимах течения для случаев воды и ВГР выражаются главным образом в том, что одинаковые режимы реализуются при более высоких значениях числа Рейнольдса для ВГР $(\Delta \mathrm{Re} \approx 20)$.

Появление новых структурных элементов волновой картины по сравнению с описанными в [7] становится заметным при $\operatorname{Re} \approx 150$. Хотя при увеличении числа Рейнольдса основным элементом волновой структуры по-прежнему являются хаотично взаимодействующие друг с другом 3D-волны, при $150<\mathrm{Re}<220$ начинает меняться сам вид этих волн. Если при меньших $\mathrm{Re}$ все гребни 3D-волн остаются гладкими (рис. 1, $a$ ), то при увеличении $\mathrm{Re}$ появляются 3D-волны, основной гребень которых покрыт капиллярной рябью (рис. 1,b). 


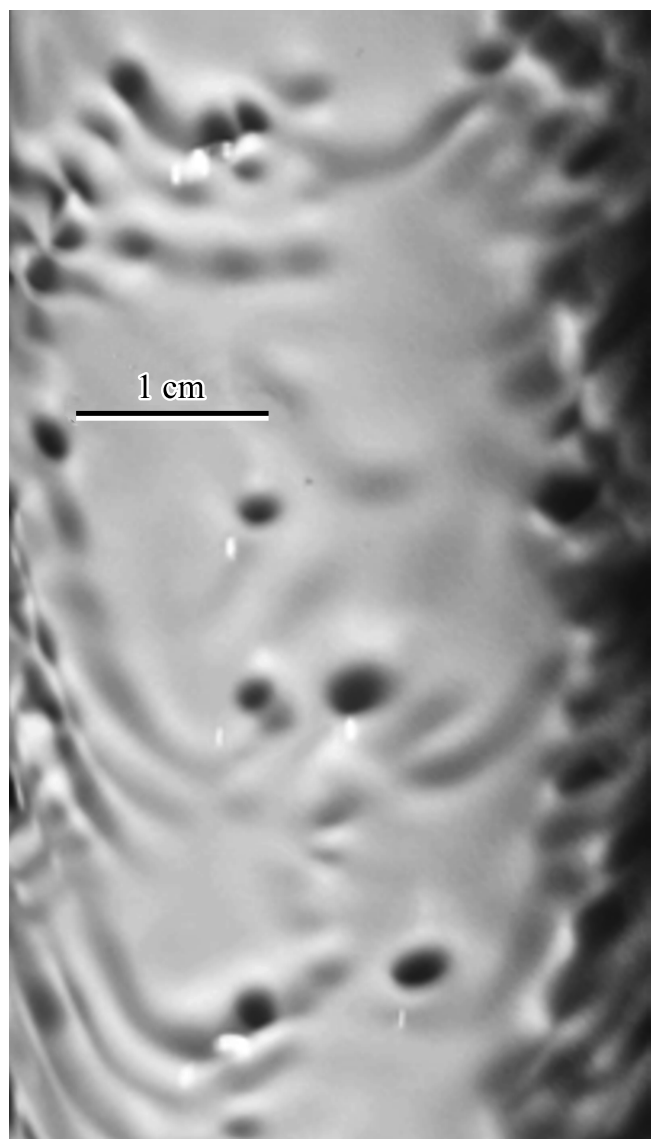

Рис. 2. Система глубоких впадин на поверхности пленки, возникшая в результате взаимодействия капиллярных предвестников трехмерных волн, ВГР, $\mathrm{Re}=220$.

Капиллярная рябь на поверхности 3D-волн возникает, как правило, вследствие их взаимодействия с малыми возмущениями на остаточном слое. После возникновения такая рябь, имеющая регулярную полосчатую или ячеистую структуру с длиной волны $1-2 \mathrm{~mm}$, быстро захватывает бо́льшую часть волны и смещается к ее заднему склону, одновременно затухая. Время жизни ряби составляет несколько сотых долей секунды. После ее затухания гребень волны становится гладким. Максимальная амплитуда капиллярной ряби зафиксирована на уровне $0.25 \mathrm{~mm}$ при характерном значении толщины пленки в гребне волны 0.9-1.1 mm для режимов в области $\operatorname{Re} \sim 200$. При дальнейшем увеличении числа Рейнольдса капиллярные структуры на гребнях 3D-волн начинают терять регулярность (рис. 1,c). Их максимальная амплитуда снижается до $0.1 \mathrm{~mm}$. Одновременно появляется все больше волн, взаимодействие которых с возмущениями на остаточном слое или между собой происходит настолько часто, что капиллярная рябь от предыдущего возмущения не успевает затухнуть. В результате поверхность таких волн оказывается покрытой хаотической рябью и принимает вид областей, занятых турбулентным движением жидкости. На фоне капил- лярных предвестников, захватывающих большие участки поверхности гладкой пленки между большими волнами, эти области не выделяются при спектральной обработке: они вносят небольшой вклад в тех же областях спектра, что и волны капиллярного предвестника.

По достижении режимов $\mathrm{Re}>400$ поверхность подавляющей части трехмерных волн покрыта хаотической капиллярной рябью, которую можно считать признаком перехода к гидродинамической турбулентности.

Интересной особенностью в исследованном диапазоне $\mathrm{Re}$ также является образование системы углублений округлой формы - „кратеров“ с поперечными размерами 1-3 mm (рис. 2), возникающих в областях взаимодействия капиллярных предвестников соседних 3Dволн. После образования такие структуры движутся по остаточному слою как независимые элементы и исчезают в процессе взаимодействия при встрече с 3D-волной. Характерное время жизни „кратеров““ составляет $0.1 \mathrm{~s}$. По данным ЛИФ-измерений толщина пленки в их центре на $0.2-0.3 \mathrm{~mm}$ меньше, чем в окружающей жидкости.

Таким образом, анализ экспериментальных данных показывает, что переход к обычной гидродинамической турбулентности при пленочном течении жидкости может начинаться с генерации высокочастотной капиллярной ряби на поверхности отдельных трехмерных волн. Что касается другого типа мелкомасштабных структур - „кратеров“ с пониженной толщиной остаточного слоя, то их влияние на волновые процессы неочевидно. С одной стороны, они являются дополнительным источником возмущений, приводящих к возникновению капиллярной ряби на крупных волнах. С другой стороны, их количество хотя и возрастает с числом Рейнольдса, но остается в исследованном диапазоне расходов довольно малым по сравнению с другими источниками возмущений. Возможно, их роль проявится при дальнейшем увеличении числа Рейнольдса.

\section{Финансирование работы}

Работа выполнена в рамках государственного задания ИТ СО РАН и при финансовой поддержке Российского фонда фундаментальных исследований (проект № 18-01-00682).

\section{Конфликт интересов}

Авторы заявляют, что у них нет конфликта интересов.

\section{Список литературы}

[1] Алексеенко С.В., Накоряков В.Е., Покусаев Б.Г. Волновое течение пленок жидкости. Новосибирск: Наука, 1992. 256 с.

[2] Mukhopadhyay S., Chhay M., Ruyer-Quil C. Modelling transitional falling liquid films // 23 Congres Francais de Mecanique. Lille, France, 2017. 9 p.

[3] Liu J., Schneider J.B., Gollub J.P. // Phys. Fluids. 1995. V. 7. N 1. P. 55-67. 
[4] Kharlamov S.M., Guzanov V.V., Bobylev A.V., Alekseenko S.V., Markovich D.M. // Phys. Fluids. 2015. V. 27. N 11. P. 114106.

[5] Adomeit P., Renz U. // Int. J. Multiphase Flow. 2000. V. 26. N 7. P. $1183-1208$.

[6] Park C.D., Nosoko T. // AIChE J. 2003. V. 49. N 11. P. 2715 2727.

[7] Guzanov V.V., Bobylev A.V., Hienz O.M., Kharlamov S.M., Kvon A.Z., Markovich D.M. // Int. J. Multiphase Flow. 2018. V. 99. P. 474-484.

[8] Demekhin E.A., Kalaidin E.N., Kalliadasis S., Vlaskin S.Y. // Phys. Fluids. 2007. V. 19. N 11. P. 114103. 